\title{
Flashover discharges dynamic with continuous and discontinuous pollution layer under lightning impulse stress
}

\author{
Mohammed El Amine Slama ${ }^{1}$ (D) Abderrahmane Beroual ${ }^{2}$
}

Received: 12 October 2020 / Accepted: 1 March 2021 / Published online: 12 April 2021

(c) The Author(s) 2021

\begin{abstract}
The paper is aimed at the study of the dynamic of discharges propagating at the surface of flat PVC insulator (i) with uniform continuous pollution layer and (ii) with uniform discontinuous pollution layer of different conductivities, under lightning impulse voltage for both polarities. It is shown that the morphology of discharges, the current and the voltage as well as the discharge velocity depend on the polarity of voltage, the configuration and the conductivity of the pollution layer; and the behavior of discharges is similar to that of discharges in long air gaps.
\end{abstract}

Keywords Polluted insulator $\cdot$ Corona/streamer $\cdot$ Spark/partial arc $\cdot$ Discharge velocity

\section{Introduction}

Investigation of lightly polluted insulator flashover (FOV) represents a great interest for the insulation design of electrical power grid. Overvoltages and travelling waves induced during switching impulse (SI) or lightning impulse (LI) stressed the equipment especially with the ground rise potential. The direct consequence is the flashover of wetted or lightly polluted insulators. In [1-3], it was shown that the FOV voltage depends on the voltage polarity, the pollution conductivity. On the other hand, the pollution continuity plays an important role on FOV process [4-7].

Many mechanisms have been proposed to explain the FOV discharge process and propagation in dc and ac. The relevant ones are given as follows: the progressive ionization [8], the dielectric breakdown [9], the thermal force [10], the electrostatic force [1] and the progressive ionization associated with partial dielectric breakdown [2, 3]. Other explanations have been proposed in recent years based on the same previous approaches [11]. For this purpose, different

Mohammed El Amine Slama

slamame@ cardiff.ac.uk

1 Advanced High Voltage Engineering Centre, School of Engineering, Cardiff University, The parade, Cardiff, Wales CF24 3AA, UK

2 AMPERE Lab CNRS UMR 5005, Ecole Centrale de Lyon, University of Lyon, 36 Avenue Guy de Collongue, 69134 Ecully, France experimental studies have been conducted to follow the FOV discharge propagation. In [2] and [11], the discharge dynamic is tracked based on the electrical current flowing across the pollution layer that can be associated with photomultiplier along the discharge path [12-14]. In [11, 13, 15] streak rapid camera was used and in [16] spectroscopic measurements have been performed. Other researchers combined electrical measurement and optical characterization in order to correlate the signals $[15,17,18]$.

Many authors proposed relationship of the FOV discharge velocity. We will retain that one which is the most interesting from our viewpoint

$v_{d}=\mu E_{d}$

and

$v_{d}=\mu\left(E_{\mathrm{pr}}-E_{d}\right)$

With

$E_{\mathrm{pr}}=\frac{I \rho_{p}}{2 e_{p} b}\left[\frac{\operatorname{sh}\left(\frac{2 \pi a_{d}}{b}\right)}{\operatorname{ch}\left(\frac{2 \pi a_{d}}{b}\right)}+1\right]$

where $\mu$ is the electron mobility, $E_{d}$ and $E_{\mathrm{pr}}$ are, respectively, the discharge electrical gradient and the pollution electrical gradient at the discharge root. $e_{p}, b, I, \rho_{p}$, and $a_{d}$ are the pollution layer depth, the polluted channel width, the discharge 
current, the pollution resistivity and the discharge radius, respectively.

Equation (1) was proposed by Anjana and Lakshminarasimha [19] and indicates that the discharge velocity depends on the electron mobility $\mu$ within the discharge and its electrical gradient $E_{d}$. Equation (2) was proposed by Rahal [1]. The discharge displacement is assumed to be governed with the ions extracted from the discharge body and the average velocity of those ions is proportional to the electrical gradient at the discharge $E_{\mathrm{pr}}$ On the other hand, a restoring force from the discharge column is exerted on these ions. Then, the resultant electrical gradient is the difference between $E_{\mathrm{pr}}$ and $E_{d}$.

According to Beroual [20], Dhahbi and Beroual [21], and Fofana and Beroual [22], the total energy injected in the system $W_{t}$, is consumed with different forms. A part of this energy is transferred to the discharge channel as a kinetic energy enabling a partial displacement $d x$ of discharge.

$W_{t}=\beta W_{c}$

where $\beta$ is the energy fraction used for the discharge propagation and varies between 0 and 1 .

During a time $\mathrm{d} t$, the mass $m_{d}$ of the elementary channel added to the discharge channel is equal to the product of the gas density $M_{v}$ multiplied by the added volume $\left(\pi a_{d}^{2} \mathrm{~d} x\right)$ such as.

$m_{d}=M_{v} \pi a_{d}^{2} \mathrm{~d} x$

and the kinetic energy is

$W_{c}=\frac{1}{2} m_{d} v_{d}^{2}=\frac{1}{2} M_{v} \pi a_{d}^{2} \mathrm{~d} x \cdot v_{d}^{2}$

where $v_{d}$ in the translation velocity of the discharge.

By substituting (5) in (6), it yields

$\frac{1}{2} M_{v} \pi a_{d}^{2} \mathrm{~d} x \cdot v_{d}^{2}=\beta \frac{\mathrm{d} W(t)}{\mathrm{d} t}$

Thus, the instantaneous discharge velocity of the discharge will be

$v_{d}(t)=\sqrt[3]{\frac{2 \beta P(t)}{M_{v} \pi a_{d}^{2}}}$

where $P(t)$ is the discharge power during a lap time $\mathrm{d} t$.

This paper presents an investigation of the FOV discharge propagation dynamic under LI stress $1.2 / 50 \mu$ s for both polarities with a continuous and discontinuous pollution layers with different conductivities. Optical and electrical investigations of the discharge morphology, the propagation dynamic and the discharge velocity will be carried out for a continuous uniform pollution layer. In the case of

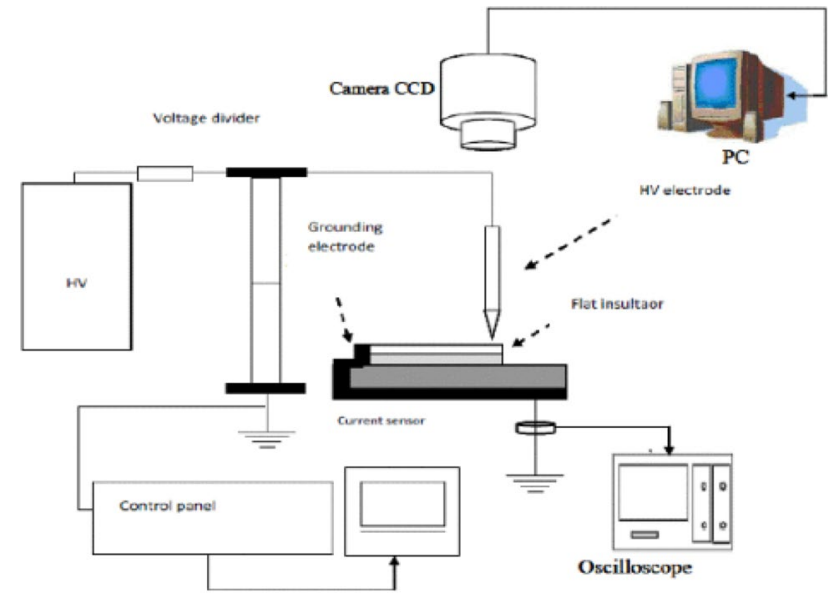

Fig. 1 Experimental setup

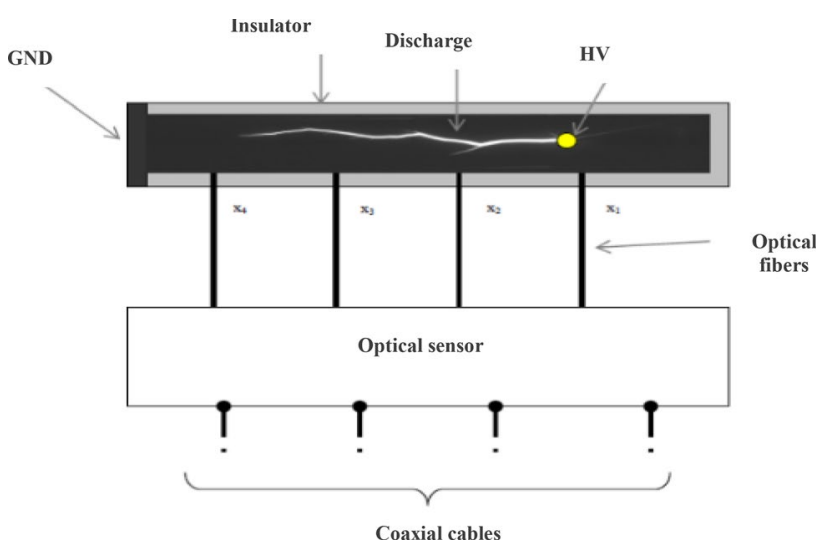

Fig. 2 Arc detector principal

discontinuous pollution layer, a focus about the discharges behavior and morphology will be achieved.

\section{Experimental setup and methodology}

The experimental setup consists of a Marx generator $(220 \mathrm{kV}-2 \mathrm{~kJ}-1.2 / 50 \mu \mathrm{s})$ that provides a standard lightning impulse (LI) voltage, a control panel, the investigated insulator and a data acquisition system (Fig. 1). The current associated with the discharges is measured thanks to a current probe (Tektronix-30 MHz). The displacement of the discharge is measured thanks to an arc detector connected to optical fibers $(\mathrm{OF})$ placed at different positions $\mathrm{Xi}$ on the insulator surface (Fig. 2). The positions of OF are chosen for detecting and correlating the optical signal and the current. The average discharge velocity is measured between two successive positions $\mathrm{Xi}$ and $\mathrm{Xi}+1$ corresponding to time ti and $\mathrm{ti}+1$. 
The arc detector consists of an optoelectronic circuit and a fluorescent OF which is the sensor [23]. It is sensitive to a radial incident light flux and reemits mainly in the axial direction. The used detecting fiber reemits mainly in the red frequencies. This choice is only justified by the sensitivity range of the optoelectronic receiver (ref. H P 2502, Hewlett Packard) used, the maximum sensitivity of which is at $670 \mathrm{~nm}$. The fiber $(1 \mathrm{~m}$ maximum length), well-polished at its extremities, is soldered to a PMMA transparent plastic fiber, which serves as a waveguide and permits the transmission of information at long distances, while ensuring a perfect electrical insulation. The optical signals are visualized and recorded with a high-resolution Agilent Technologies MSO6104A $1 \mathrm{GHz}$ oscilloscope and post-processed by using conventional office software. The OF are arranged at the following distances from the $\mathrm{HV}$ needle: $\mathrm{O}_{1}-1 \mathrm{~cm}, \mathrm{O}_{2}-2 \mathrm{~cm}, \mathrm{O}_{3}-7 \mathrm{~cm}$ and $\mathrm{O}_{4}-12 \mathrm{~cm}$.

The current and the voltage are visualized and recorded with a high-resolution Tektronix DSA601A $60 \mathrm{MHz}$ oscilloscope connect to a PC and the data a post-processed by using WaveStar software. The discharges are observed with a SGVA Sony HC-HR58 high-resolution (767X580 pixels) CDD camera connected to a PC via a Meteor II /Multichannel acquisition card.

The insulator model consists of a rectangular channel made of PVC with $1.8 \mathrm{~cm}$ depth, $5 \mathrm{~cm}$ width $\mathrm{b}$ and a total leakage length $L$ of $20 \mathrm{~cm}$ (Fig. 3a). One of the ends of this experimental model is in contact with a grounded electrode consisting of a band of aluminum. The high voltage (HV) electrode consists of a point made of tungsten which overhangs the electrolyte at a height $\mathrm{h}$ of $1 \mathrm{~mm}$; it is placed at a distance $L=14 \mathrm{~cm}$ from the ground electrode (GND). In the case of discontinuous pollution layer, the insulators are constituted of partial polluted bands and dry/clean bands (Fig. 3b, c). Two discontinuous pollution layer distribution are considered: two dry bands and two polluted bands (2DB2PB) and three dry bands and three polluted bands (3DB3PB). The dimensions of each band are given in Fig. 3.

\section{Results and discussion}

In this part, results and discussion will be presented for both of continuous and discontinuous pollution layer distribution. In first part, focus on the discharge propagation dynamic and discharge velocity in the case of uniform continuous pollution layer is presented. The second part focus on the discharge morphology and dynamic according to the pollution distribution.

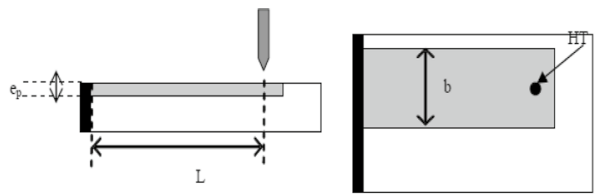

(a) Continuous Pollution.

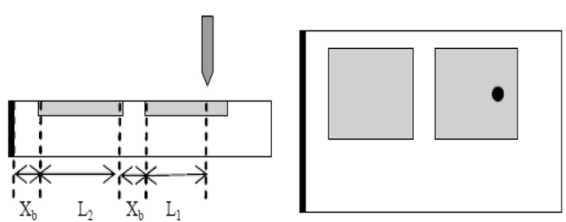

(b) Discontinuous Pollution with 2 Dry Bands and 2 Polluted Band (2DB2PB) with $\mathrm{L} 1=\mathrm{L} 2=4 \mathrm{~cm}$ and $\mathrm{Xb}=1$ $\mathrm{cm}$.

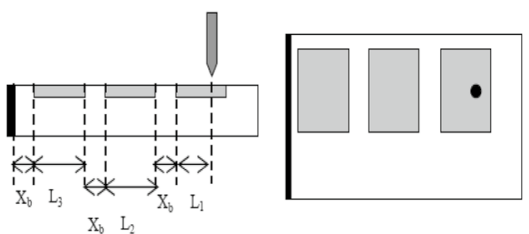

(c) Discontinuous Pollution with 3 Dry Bands and 3 Polluted Band (3DB3PB) with $\mathrm{L} 1=\mathrm{L} 2=\mathrm{L} 3=3 \mathrm{~cm}$ and $\mathrm{Xb}$ $=1 \mathrm{~cm}$.

Fig. 3 Insulators models. a Continuous pollution. b Discontinuous pollution with 2 dry bands and 2 polluted band (2DB2PB) with $\mathrm{L} 1=\mathrm{L} 2=4 \mathrm{~cm}$ and $\mathrm{Xb}=1 \mathrm{~cm}$. $\mathrm{c}$ Discontinuous Pollution with 3 dry bands and 3 polluted band (3DB3PB) with $\mathrm{L} 1=\mathrm{L} 2=\mathrm{L} 3=3 \mathrm{~cm}$ and $\mathrm{Xb}=1 \mathrm{~cm}$

\subsection{Discharge morphology, discharge velocity and propagation dynamic}

Figures 4 and 5 illustrate the static photographs of the discharge propagation seen from above for conductivities 10 $\mu \mathrm{S} / \mathrm{cm}$ and $100 \mu \mathrm{S} / \mathrm{cm}$ for both polarities. The discharge presents a cylindrical channel shape whose diameter decreases at its head whatever the polarity and the conductivity. The body of the discharge (column) is brighter than its head. The head of the discharge has ramifications (streamers) that are the consequence of an ionization at the front of the discharge head and at the vicinity of its column. This could be due to the intensification of the electrical gradient of the pollution layer and to the radiation of the discharge which would cause photoemission from the electrolyte (pollution). The radius of the discharge increases with the conductivity of the pollution and therefore with the current.

The discharge is not straight, there is a pronounced tortuosity depending on the polarity of the needle; it is more tortuous with a positive needle than with a negative needle. Note that the discharge follows a straight line during the final jump (Fig. 6). This final jump is mainly done in the air directly with the ground electrode regardless of the portion of the liquid remaining. This would explain 


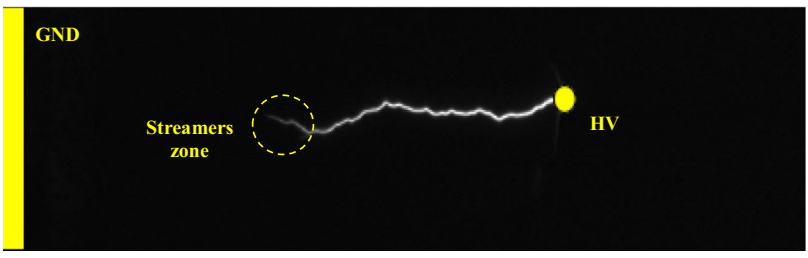

Positive Polarity.

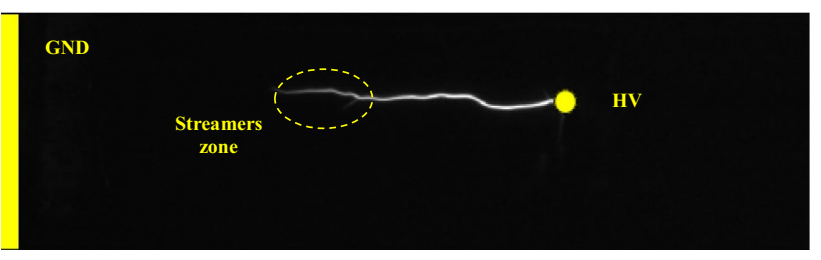

Negative Polarity

Fig. 4 Statics photographs of the discharge propagation with. pollution conductivity $10 \mu \mathrm{S} / \mathrm{cm}$

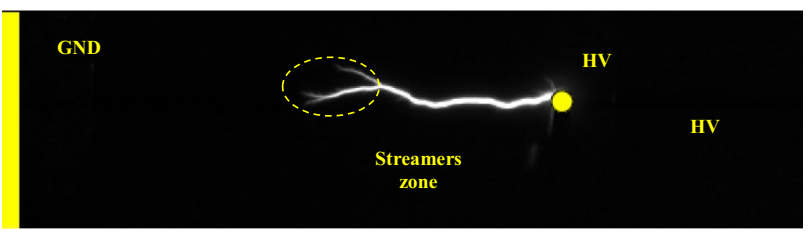

Positive Polarity

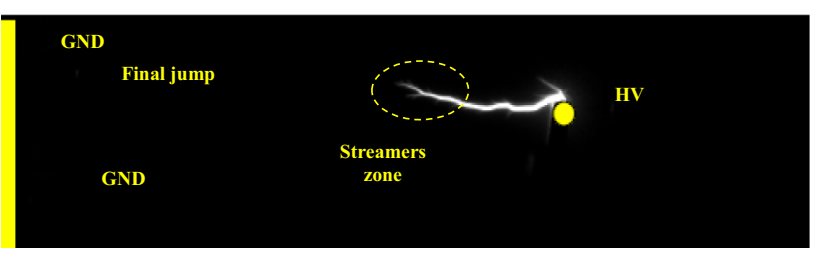

Negative Polarity

Fig. 5 Statics photographs of the discharge propagation with. pollution conductivity $100 \mu \mathrm{S} / \mathrm{cm}$

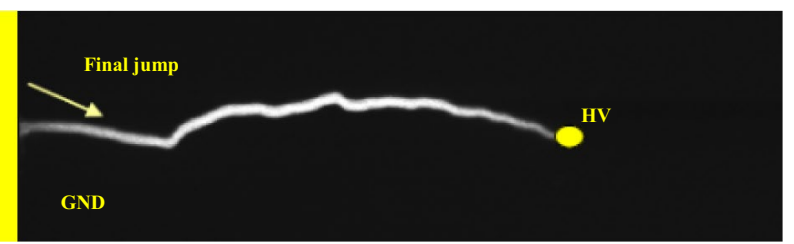

Fig.6 Final jump and flashover

the sharp rise in current before the establishment of the arc regime since the electronic emission would be made directly from the metal electrode.

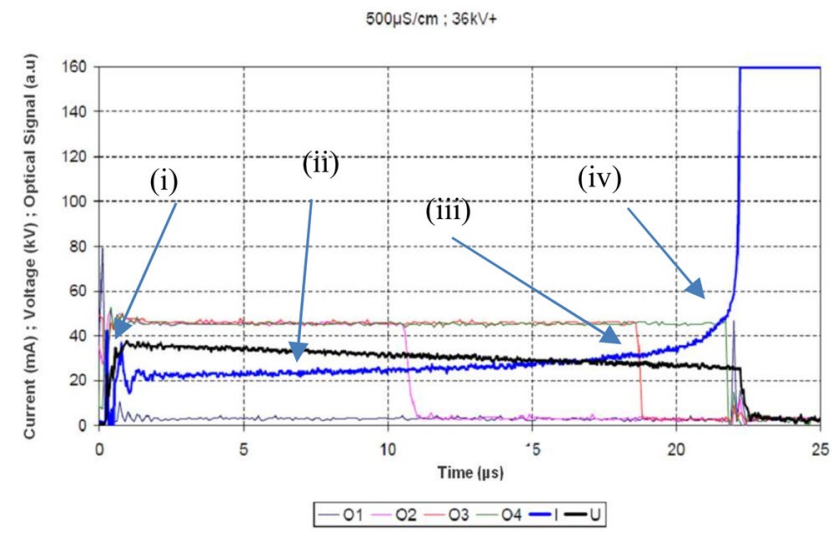

Fig. 7 Current, voltage and optical signals acquisition during the discharge propagation and flashover with a continuous pollution $500 \mu \mathrm{S} /$ $\mathrm{cm} 36 \mathrm{kV}$ positive lightning impulse

Figure 7 illustrates an example of the acquired current, voltage and optical signal of arc detector during FOV process for a $500 \mu \mathrm{S} / \mathrm{cm}$ pollution conductivity with $36 \mathrm{kV}$ applied positive LI. The current contains four steps:

(i) Inception transient current with high pulses corresponding to corona/streamers inception [23]. The density of the current pulses depends on the voltage polarity and the pollution conductivity. The duration of this step is around $1 \mu$ s before the discharge evolved to spark or partial arc.

(ii) Propagation step where the current slightly increases while the voltage decreases. This current is different than the previous one because the discharge regime changes from corona/streamer to spark/partial arc. The magnitude and the duration of this step depend on the pollution conductivity and the voltage polarity. The current magnitude is related to the injected charges from the pollution into the discharge column.

(iii) The critical current step corresponds to the phase preceding the final jump of the discharge and represents the current for which the system becomes unstable and evolves toward FOV. It corresponds to a critical length of the discharge between $\mathrm{L} / 2$ and $2 \mathrm{~L} / 3$.

(iv) Transition current or FOV current corresponds to the final jump leading to FOV. In this case, the current increases very quickly the voltage also drops suddenly. This current corresponds to the short circuit, in other words, to the transition to the arc regime when the discharge reaches the ground electrode.

According to Fig. 7, the discharge appears during the voltage rise and begins to propagate with a slightly increasing current (from $\mathrm{O} 1$ to $\mathrm{O} 2$ ). The second stage of the propagation concerns the $\mathrm{OF} \mathrm{O} 3$ where the current is more intense. At $\mathrm{O} 4$, the current growth up suddenly and corresponds to 


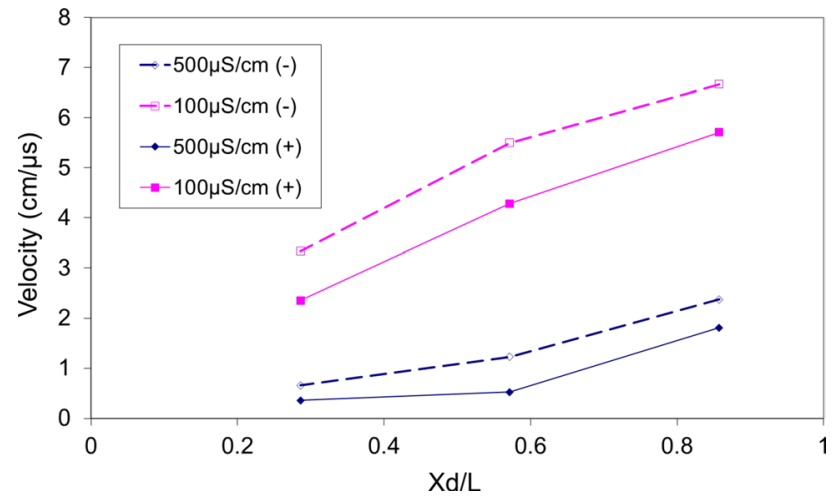

Fig. 8 Variation of the discharge velocity vs the creepage length for different conductivities on both polarities

the FOV current. According to Fig. 7, the FOV critical conditions are situated between OF $\mathrm{O} 3$ and O4. In this segment, the discharge reaches the critical length that is around $\mathrm{L} / 2$ and $2 \mathrm{~L} / 3$.

Figure 8 illustrates the average velocities of the FOV discharge for different pollution conductivities on both polarities. According to this figure, the discharge velocity for negative polarity is higher than positive polarity whatever the pollution conductivity. On the other hand, the discharge is faster when it closer the ground electrode that means that the discharge accelerates when it reaches the critical length. Similar observations have been related by other researchers.

Figures 9 and 10 present the correlation between the measured velocities and the calculated one based on Eqs. (1), (2) and (8) for different conductivities and voltage polarities. According to those figures, the velocity calculated with Eqs. (1) and (2) is lower than the measured one whatever the value of the mobility $\mu$. On the other hand, by using Eq. (8) and considering $\beta$ equal to $10 \%$ constant during all the extension of the discharge shows a discharge velocity different from those measured. The fraction of energy necessary for propagation, $10 \%$ of the total energy of the system, used is too large than it should be. This is why it obtains very high velocities and therefore low FOV times. This suggests that the coefficient $\beta$ is not constant as reported in [21, 22].

From these results, one conclude that the fraction of total energy consumed in kinetic energy changes with the length of the discharge and therefore with time during the discharge propagation. By considering that coefficient $\beta$ in Eq. (8) is not constant and varies with polarity and time, new plots are made in Figs. 8 and 9. According to those results, one can conclude that during the propagation phase this fraction of total energy consumed in kinetic energy is small, while during the acceleration phase, it becomes more and more important with the increase of the total power. Thus, with positive polarity, $\beta$ varies from 0.1 to $15 \%$ when it is negative $\beta$ varies from 0.5 to $30 \%$. Then, the kinetic energy increases with the
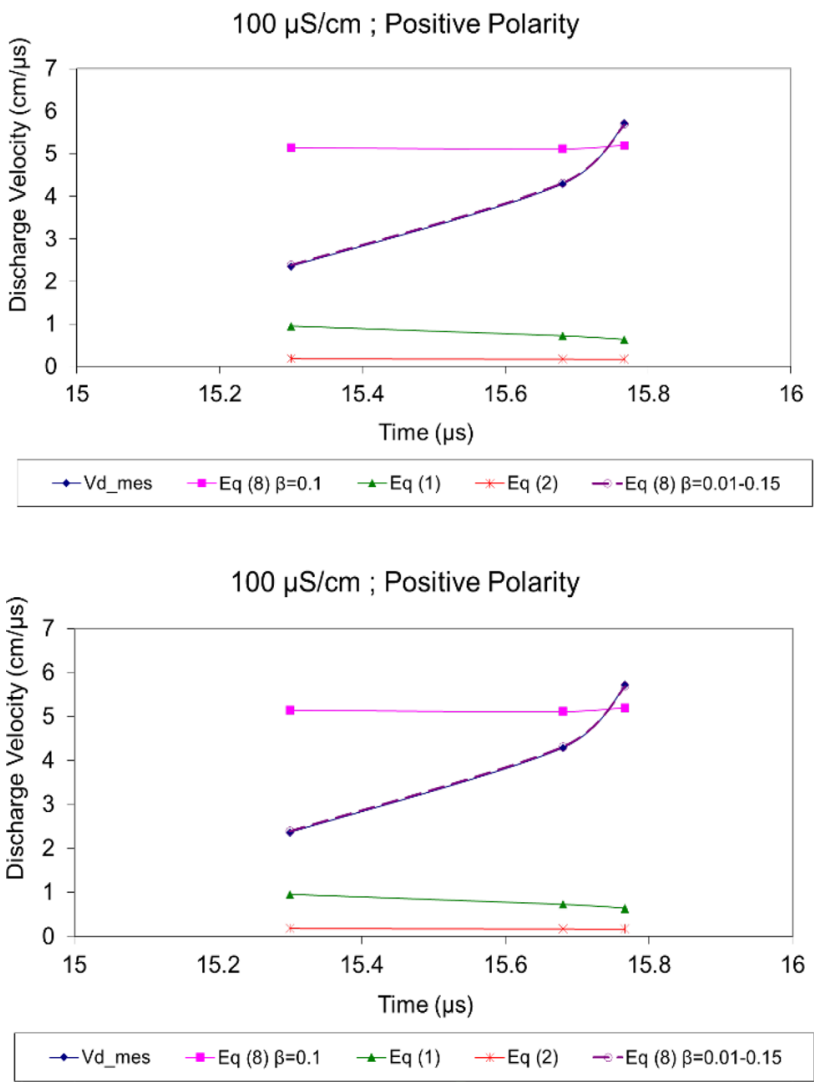

Fig. 9 Comparison of measured and calculated discharge velocity on both polarities for a $100 \mu \mathrm{S} / \mathrm{cm}$ pollution layer

extension (propagation) of the discharge. Note that the range of kinetic energy variations depends on the applied polarity and the conductivity of the pollution deposit.

From the electrical and optical measurements, critical time was estimated and corresponding to the critical length of the discharge. Table 1 illustrates an example of the average critical time $T_{\text {cri }}$ and the FOV time $T_{\mathrm{FOV}}$ in the two polarities for pollution conductivities equal to $10 \mu \mathrm{S} / \mathrm{cm}$ and 100 $\mu \mathrm{S} / \mathrm{cm}$. The average critical time is estimated from the optical measurement of the displacement of the discharge. When the discharge is between measurement points $\mathrm{O}_{2}$ and $\mathrm{O}_{3}$, its length will be between $\mathrm{L} / 2$ and $2 \mathrm{~L} / 3$ which correspond to the critical length of the discharge. According to this table, the critical conditions are reached after a time equal to $9 / 10$ of the total $\mathrm{T}_{\mathrm{FOV}}$ on both polarities. The remaining $1 / 10$ of time is specific to the final jump from the discharge to the opposite electrode. This result is similar to the observation concerning d.c. FOV [24].

Consequently, the FOV time consists of two parts:

(i) A propagation time when the discharge develops slowly on the electrolyte to its critical length (i.e. $1 / 2$ and $2 / 3$ of the length of leakage). During this time interval ( $9 / 10$ of the $\left.T_{\mathrm{FOV}}\right)$, the discharge evolves 

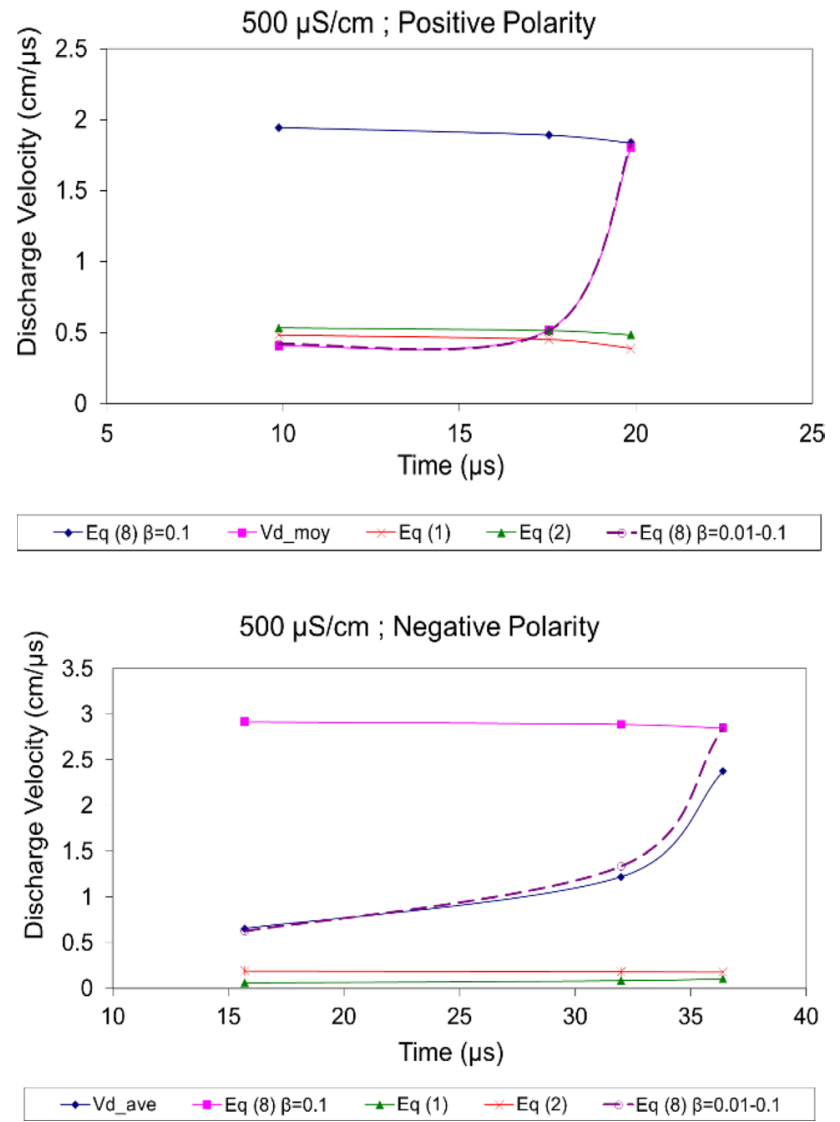

Fig. 10 Comparison of measured and calculated discharge velocity on both polarities for a $500 \mu \mathrm{S} / \mathrm{cm}$ pollution layer

Table 1 Critical time and FOV time

\begin{tabular}{lllll}
\hline $\begin{array}{l}\text { Conductivity }(\mu \mathrm{S} / \\
\mathrm{cm})\end{array}$ & 10 & 10 & 100 & 100 \\
\hline Polarity & + & - & + & - \\
$T_{\text {cri }}(\mu \mathrm{s})$ & 4.55 & 10.85 & 15.7 & 16 \\
$T_{\mathrm{FOV}}(\mu \mathrm{s})$ & 5 & 12 & 17 & 17.5 \\
$T_{\text {cri }} / T_{\mathrm{FOV}}$ & 0.91 & 0.90 & 0.92 & 0.91 \\
\hline
\end{tabular}

with a relatively low kinetic energy since the fraction of the energy is less than $10 \%$ of the total energy,

(ii) A second propagation time with rapid jump of the discharge through the air to the opposite electrode. The dielectric breakdown of the remaining interval would be made even easier by the proximity of the electrode and of the charges injected into the interelectrode interval. During this phase, the kinetic energy of the discharge growth up to $30 \%$ of the total energy. This increase in kinetic energy follows the change in regime of the nature of the discharge accompanied by a sudden increase in power (and temperature).

\subsection{Discharge dynamic with discontinuous pollution layer Effect of Immersion}

In this case, several discharges appear almost simultaneously (Figs. 11a, b): a single-trunk (or single-column) or multitrunk discharge at the HV electrode and other discharges at the dry bands. The discharges have ramifications at their head and these ramifications are less bright than the columns and present similitudes with the streamers appearing in long discharges. Diampeni [7] as well as in Belosheev [25] and Anpilov et al. [26] observed similar behavior by using different laboratory insulator models than the used one. Note that several multi-trunk discharges in parallel appears.

The direction of propagation of the discharges varies according to the polarity of the HV electrode. In positive polarity, the discharges propagate from the HV electrode and the dry bands to the discharge situated at the ground electrode. In negative polarity, the discharges move from

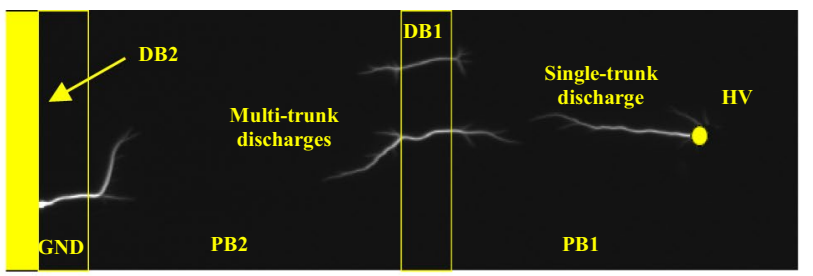

Positive Polarity

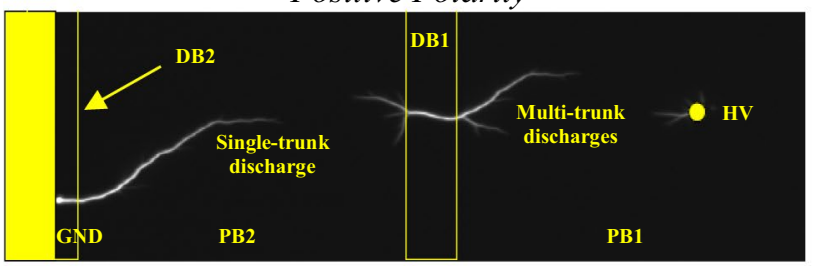

Negative Polarity

(a) $2 D B 2 P B$ Pollution conductivity $10 \mu \mathrm{S} / \mathrm{cm}$
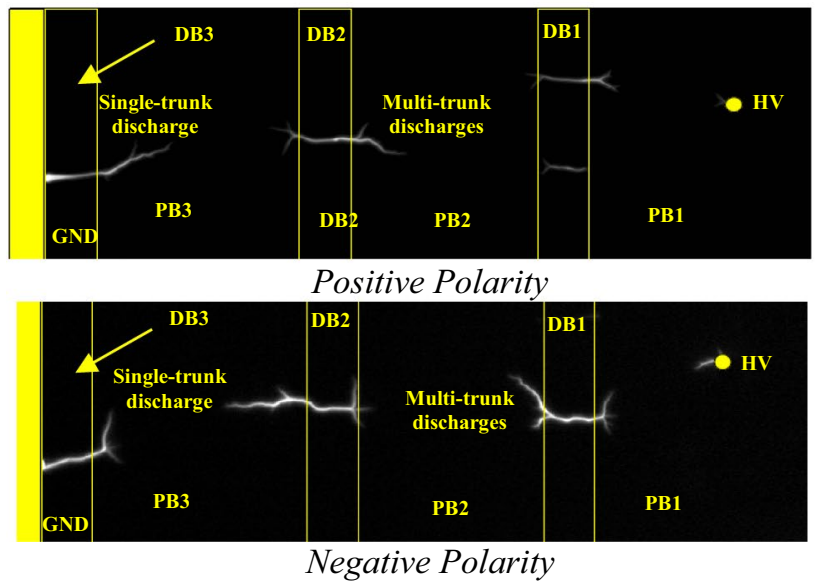

(b) $3 D B 3 P B$ Pollution conductivity $100 \mu \mathrm{S} / \mathrm{cm}$

Fig. 11 Statics photographs of the discharge propagation with discontinuous pollution layer. a 2DB2PB Pollution conductivity $10 \mu \mathrm{S} / \mathrm{cm}$, b 3DB3PB Pollution conductivity $100 \mu \mathrm{S} / \mathrm{cm}$ 
the ground to the HV electrode. In general, the discharges at the dry bands are longer than those located at the needle. The discharges have the same characteristics (ramifications, appearance and radius) as those observed in the case of uniform pollution on both polarities. FOV is achieved when all the partials arcs connect to each other.

Figures 12 and 13 illustrate the oscillograms of the current and the voltage for discontinuous pollution 2DB2PB and 3DB3PB. The first observation made is that those configurations are more complex than the uniform continuous pollution layer (Fig. 6). According to Figs. 12 and 13, that the current goes through several stages whatever the polarity of the voltage:

(i) Initiation of the corona discharge with a more or less high density of current pulses during the rise time of the applied voltage. The current pulse density is a function of the polarity of the HV electrode and the conductivity of the pollution. It is less dense when the point is negative, and it also decreases with increasing conductivity of the pollution.

(ii) Stabilization of the current for a certain time revealing a first level.

(a)

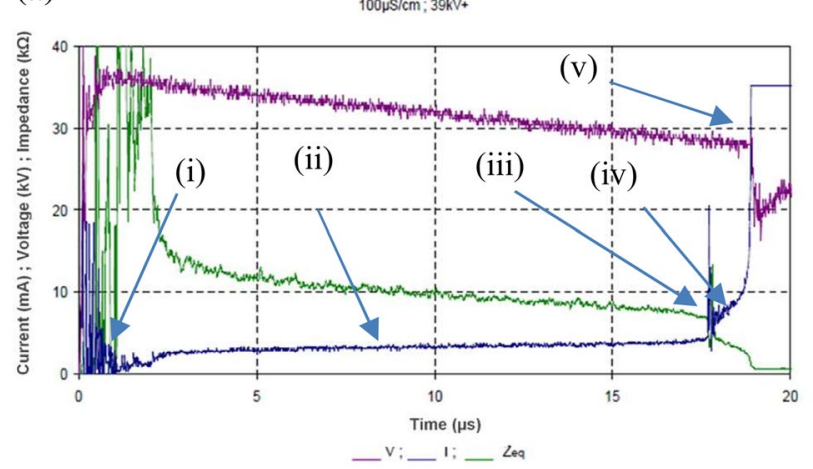

(b)

$100 \mathrm{uS} / \mathrm{cm} ; 37 \mathrm{kV}-$

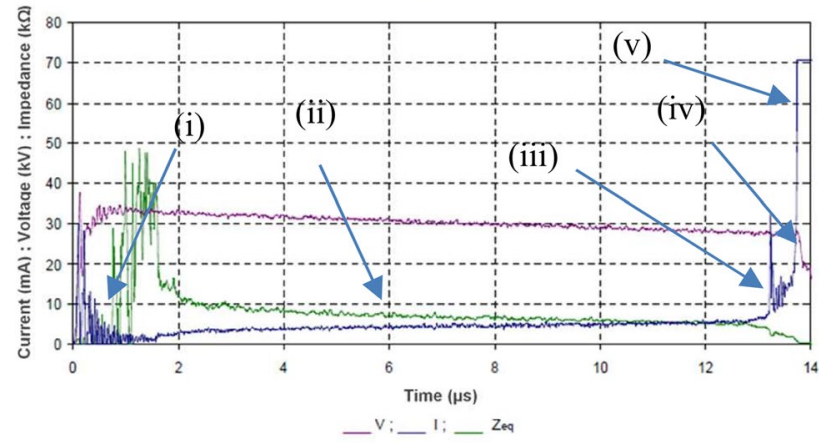

Fig. 12 Oscillogram of current, voltage and equivalent impedance for 2DB2BP discontinuous pollution with conductivity $100 \mu \mathrm{S} / \mathrm{cm}$ on both polarities. a Positive LI. b Negative LI

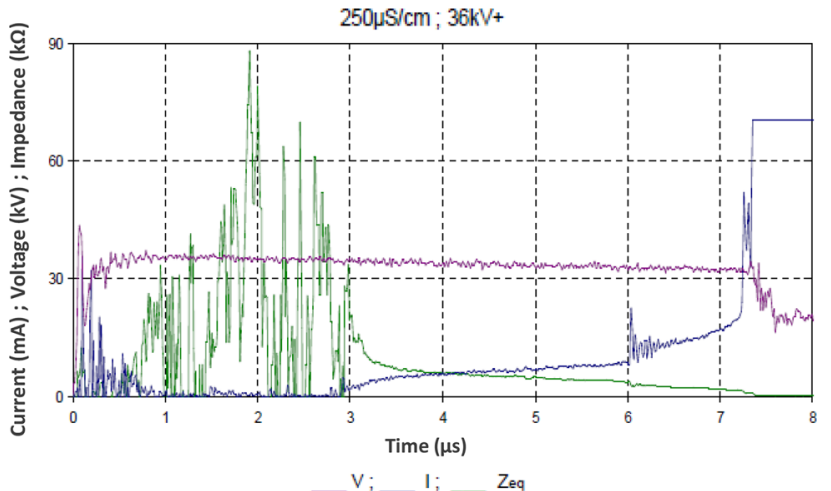

(a) Positive LI.

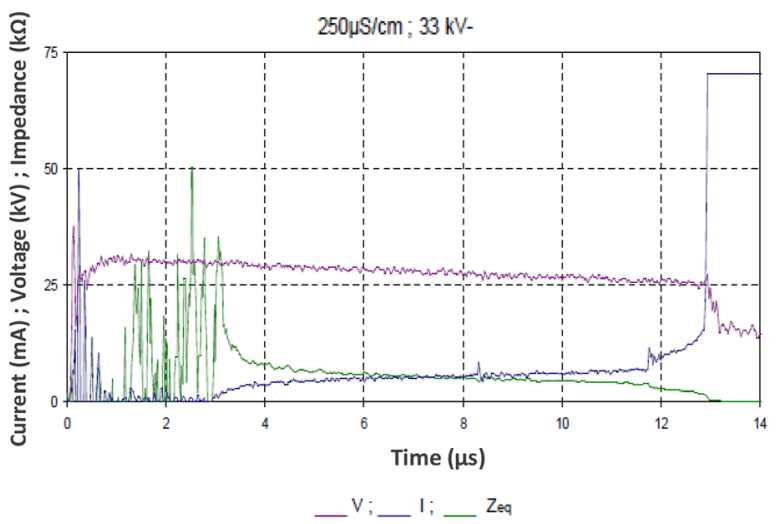

(a) Negative LI.

Fig. 13 Oscillogram of current, voltage and equivalent impedance for 3DB3BP discontinuous pollution with conductivity $250 \mu \mathrm{S} / \mathrm{cm}$ on both polarities. a Positive LI. b Negative LI

(iii) Apparition of a second level corresponding to a large current draw for a very short time and then seeing a stabilization of the current. This current level corresponds to the connection of two successive discharges.

(iv) Apparition of a very rapid third level, the duration of which varies with the conductivity of the pollution and the polarity of the tip, accompanied by a sudden increase in the current.

(v) FOV the insulator with an increase in current which will only be limited by the impedance of the generator.

For a pollution configuration of the 3DB3PB type, the same current pattern is observed with additional steps (Fig. 13).

From these observations, one conclude that the structure of the discharge presents similarities with discharges in large air intervals with a less luminous stem. Indeed, in the case of air, this stem includes a high density of streamers leading to the local heating of the gas. This temperature increase causes an emission of electrons by thermo-ionization or/ and by detachment; this results in an increase in plasma 
conductivity. In our case, the corona/streamers at the discharge head seem less important than for air and one would think that most of the charge carriers come from the liquid following photoemission, secondary emission, thermoemission and to a lesser extent of photoionization and ion spraying. This hypothesis is reinforced by the fact that the luminosity and the diameter of the discharge increase with the conductivity of the pollution whatever the polarity of the voltage.

\section{Conclusion}

This paper was aimed to the study of surface discharges and FOV dynamic along insulators with uniform continuous and uniform discontinuous pollution layer under LI voltage.

In the case of uniform continuous pollution layer, the experimental results show that discharge presents similarities with discharges in large air intervals with a less luminous stem. The morphology of those discharges depends on the voltage polarity and the diameter varies with the pollution conductivity. According to the current measurements, it has been found that the FOV process follows four different steps. Each step presents a specific current that is correlated with the change on the discharge nature: from corona/ streamer to spark/partial arc.

A distinction has been made between the critical current and FOV current. The velocity of the discharge is not constant and based on the used equations, the kinetic energy increases with the extension (propagation) of the discharge. The critical conditions of FOV are reached after $9 / 10$ of the total TFOV on both polarities. The remaining $1 / 10$ of time is specific to the final FOV.

For uniform discontinuous pollution layer, several discharges appear almost simultaneously: a single-trunk (or single-column) or multi-trunk discharge at the $\mathrm{HV}$ electrode and other discharges at the dry bands. The discharges have the same properties (morphology/diameter) as for uniform continuous pollution layer. The direction of propagation of the discharges varies according to the polarity of the HV electrode. The oscillogram of current and voltage shows that the current goes through several stages whatever the polarity of the voltage.

Open Access This article is licensed under a Creative Commons Attribution 4.0 International License, which permits use, sharing, adaptation, distribution and reproduction in any medium or format, as long as you give appropriate credit to the original author(s) and the source, provide a link to the Creative Commons licence, and indicate if changes were made. The images or other third party material in this article are included in the article's Creative Commons licence, unless indicated otherwise in a credit line to the material. If material is not included in the article's Creative Commons licence and your intended use is not permitted by statutory regulation or exceeds the permitted use, you will need to obtain permission directly from the copyright holder. To view a copy of this licence, visit http://creativecommons.org/licenses/by/4.0/.

\section{References}

1. Rahal EHAM (1979) Sur les mécanismes physiques du contournement des isolateurs HT. Thèse de Doctorat es-sciences physiques, Université Paul Sabatier, Toulouse, France

2. Flazi S (1987) Étude du contournement électrique des isolateurs haute tension pollués-Critères d'élongation de la décharge et dynamique du phénomène. Thèse de doctorat ès Sciences Physiques, University Paul Sabatier, Toulouse, France

3. Slama MEA, Beroual A, Hadi H (2013) Influence of pollution constituents on DC flashover of high voltage insulators. IEEE Trans Dielectr Electr Insul 20(2):401-408

4. Mekhaldi A, Namane D, Bouazabia S, Beroual A (1999) Flashover of discontinuous pollution layer on high voltage insulators. IEEE Trans Dielectr Electr Insul 6:900-906

5. Slama MEA, Beroual A, Hadi H (2012) The effect of discontinuous non uniform pollution on the flashover of polluted insulators under lightning impulse voltage. In: 2012 international conference on high voltage engineering and application, pp. 246-249

6. Danis J (1983) A stochastic pollution flashover model. In: 4th international symposium on high voltage engineering, Report 46-12, September 5-9, Athens, Greece

7. Diampeni Kimbakala S (2007) Modélisation dynamique des décharges se propageant sur de surfaces isolantes polluées avec des dépôts discontinus sous différentes formes de tension. $\mathrm{PhD}$ Thesis, Ecole Centrale de Lyon, France

8. Wilkins R, Al-Baghdadi AAJ (1971) Arc propagation along an electrolytic surface. Proc IEE, 118:1886-1892

9. Jolly DC, Poole CD (1979) Flashover of contaminated insulators with cylindrical symmetry under DC conditions. IEEE Trans Electr Insul 2:77-84

10. Mercure HP, Drouet MG (1982) Dynamic Measurements of the current distribution in the foot of an ARC propagating along the surface of an electrotype. IEEE Trans Power Appar Syst 3:725-736

11. Li Y, Yang H, Zhang Q, Yang X, Xinzhe Yu (2014) Pollution flashover calculation model based on characteristics of AC partial arc on top and bottom wet-polluted dielectric surfaces. IEEE Trans Dielectr Electr Insul 21(4):1735-1746

12. Matsuo H, Fujishima T, Yamashita T, Takenouchi O (1996) Propagation velocity and photoemission intensity of a local discharge on an electrolytic surface. IEEE Trans Dielectr Electr Insul 3(3):444-449

13. Yamashita T, Matsuo H, Fujiyama H, Oshige T (1987) Relationship between photoemission and propagation velocity of local discharge on electrolytic surfaces. IEEE Trans Dielectr Electr Insul 22:811-816

14. Matsuo H, Yamashita T, Shi WD (2000) Electrical contact between a local discharge on an Electrolytic Solution and the Solution Surface. IEEE Trans Dielectr Electr Insul 7(3):360-365

15. Mahi D (1986) Dynamique de l'allongement sur une surface faiblement conductrice d'une décharge alimentée en courant alternatif. Thèse de Doctorat Ingénieur, Université Paul Sabatier Toulouse, France

16. Matsumoto T, Ishi M, Kawamura T (1984) Optoelectronic measurement of partial arcs on contaminated surface. IEEE Trans Electr Insul 19:531-548 
17. Pissalto Filho J (1986) Analyse du Contournement d'une Surface Faiblement Conductrice par une Decharge Electrique Alimentee en Courant Continu. Thèse de Doctorat es-Sciences Physiques, Université Paul Sabatier, Toulouse, France

18. Pollentes M (1996) Sur l'Utilisation de Modèles de Laboratoire pour l'Etude de la Tenue au Contournement des Isolateurs Pollués. Thèse de Doctorat en Génie Electrique, Université Paul Sabatier, Toulouse, France

19. Anjana S, Lakshminarasmha CS (1989) Computed of flashover voltages of polluted insulators using dynamic arc model. In: 6th international symposium on high voltage engineering, Paper 30-09, New Orleans, USA

20. Béroual A (1993) Electronic gaseous process in the breakdown phenomena of dielectric liquids. J Appl Phys 73(9):4528-4533

21. Dhahbi-Megriche N, Beroual A (2000) Dynamic model of discharge propagation on polluted surfaces under impulse voltages. IEE Proc Gener Transm Distrib 147(5):279-284
22. Fofana I, Beroual A (1996) A new proposal for calculation of the leader velocity based on energy considerations. J Phys D Appl Phys 29:691-696

23. El-A M, Slama A, Beroual AG, Vinson P (2016) Creeping discharge and flashover of solid dielectric in air at atmospheric pressure: experiment and modelling. IEEE Trans Dielectr Electr Insul 23(5):2949-2956

24. Bruggeman P, Leys C (2009) Non-thermal plasmas in and in contact with liquids. J Phys D Appl Phys 42:053001

25. Belosheev VP (1998) Study of the leader of a spark discharge over a water surface. Tech Physics 43(7):783-789

26. Anpilov AM, Barkhudarov EM, Kop'ev VA, Kossyi IA (2007) High-voltage pulsed discharge along the water surface. Electric and spectral characteristics 28. Prague, Czech Republic. ICPIG, pp 1030-1033 